\title{
Structural features and stability of Spanish sepiolite as a potential catalyst
} Aqeel Al-Ani ${ }^{\text {a }}$ *; Ralf Gertisser ${ }^{\mathrm{b}}$ and Vladimir Zholobenko ${ }^{\text {a }}$

a School of Chemical and Physical Sciences, Keele University, Keele, Staffordshire, ST5 5BG, United Kingdom

${ }^{b}$ School of Geography, Geology and the Environment, Keele University, Keele, Staffordshire, ST5 5BG, United Kingdom

\begin{abstract}
Sepiolite-based catalysts loaded with potassium hydroxide were prepared via the wet impregnation and ion-exchange methods and evaluated as catalysts in base-assisted reactions, such as transesterification of renewable oils. The structural features of these catalysts were characterised in detail by variable-temperature in situ X-ray diffraction, $\mathrm{N}_{2}$ adsorption-desorption, scanning electron microscopy with energy-dispersive X-ray analysis and in situ FTIR spectroscopy. Although a high yield of fatty acid methyl esters was achieved in transesterification reactions in the presence of Kcontaining sepiolite, this system showed significant deactivation due to its structural degradation and loss of the active component during the reaction and regeneration cycles. This work demonstrates for the first time how the thermal and structural stability of sepiolite based systems can affect their performance, which is an essential issue that has not been sufficiently addressed in recent research related to the catalytic applications of these materials.
\end{abstract}

Keywords:

Structural stability, in situ XRD, Sepiolite, Transesterification, Microwave Catalysis

${ }^{*}{ }^{\ddagger}$ Corresponding authors:

Aqeel Al-Ani, e-mail address: a.a.t.al-ani@ keele.ac.uk

Vladimir Zholobenko, e-mail address: v.1.zholobenko@keele.ac.uk 


\section{Introduction}

Nanoporous materials have been used in a host of catalytic applications owing to their versatile pore networks, enhanced reactivity, stability, chemical functionality and high surface area (Corma et al., 2006; Somorjai and Na, 2015; Mota et al., 2016). Many studies have illustrated the use of alkaline, alkaline earth and transition metal oxides supported on nanoporous materials with the pore size of 1-100 nm, such as silicas, clays and zeolites prepared by impregnation, ion exchange and precipitation as highly active catalysts (Corma and Martin-Aranda, 1991; Gedanken et al., 2016). One of the processes for the production of an environmentally friendly fuel from vegetable oils and animal fats is the transesterification reaction between triglycerides (TGs) in oils or fats and an alcohol, which is carried out in the presence of an acid or base catalyst yielding fatty acid methyl esters (FAMEs) and glycerol. For this reaction, heterogeneous catalysis can offer a greener route with potential advantages including the elimination of the quenching step, separation of the products and associated aqueous waste (Gandía et al., 2018).

Sepiolite (Sep), often in close association and intergrowth with palygorskite, is known from many localities worldwide but is typically found in only small amount compared to other minerals that form under similar geological conditions. The low specific gravity, high porosity and capacity to float on water led to the original name ñMeerschaumò (German for ñfoam of the seaò) by Abraham Gottlob Werner. Later, based on its similarity with cuttlebone, the internal shell of cuttlefish, the name ñsepioliteò from Greek ñsepionò (cuttlebone) and ñithosò (stone) was given to the mineral for a find in the Piedmont region of Italy. Sep requires alkaline conditions, with high activities of silicon and magnesium (Singer, 1989), and is also often associated with low latitudes and arid to semi-arid climates. Environments of formation include marine, lacustrine and lagoonal continental sediments, soils, palaeosols and calcretes (Deer et al., 1992). Replacement of pre-existing minerals such as magnesite (Yeniyol, 1986), hydrothermal alteration (e.g. Ehlmann et al., 1962; Irkeç and Ünlü, 1993) and a role of biomineralisation (e.g. Leguey et al., 2010) have also been suggested for the formation of Sep. Large, economically valuable Sep deposits originate mostly from formation in shallow seas and lakes as chemical sediments. At Eskikehir (Turkey), the richest Sep mining field in the world, Sep occurs as layers and nodules in Neogene lacustrine sediments (Kadir et al., 2016). Other notable Sep occurrences are in the United States, the Czech Republic, Greece, France and Spain. The latter includes Sep-rich deposits in southern and central Spain associated with lagoonal and lacustrine environments (e.g. Galán and Ferrero, 1982; Galán and Castillo, 1984; Torres-Ruíz et al., 1994; Armenteros et al., 1995; Bustillo and Alonso-Zarza, 2007). 
Together with palygorskite, Sep is a member of the palygorskite group of clay minerals, which belong to the sheet silicate (phyllosilicate) group of the silicates (Deer et al., 1992). These minerals are characterised by the same basic building blocks, namely a tetrahedral sheet and one of two kinds of octahedral sheets, combined to form composite mineral structures. In contrast to other sheet silicates, Sep, a fibrous hydrated magnesium silicate with the ideal chemical formula $\mathrm{Mg}_{4} \mathrm{Si}_{6} \mathrm{O}_{15}(\mathrm{OH})_{2} \cdot 6 \mathrm{H}_{2} \mathrm{O}$ (the formula $\mathrm{Mg}_{8} \mathrm{Si}_{12} \mathrm{O}_{30}(\mathrm{OH})_{4} \cdot 4\left(\mathrm{H}_{2} \mathrm{O}\right) \cdot \mathrm{nH}_{2} \mathrm{O}$ is also used in the literature), lacks continuous octahedral sheets (Figure 1). The tetrahedral sheets are continuous; however, ribbons rather than sheets of octahedra leave channels $(0.36 \times 1.06 \mathrm{~nm}$ in size $)$ in the Sep structure that can accommodate water and organic molecules (Deer et al., 1992). Furthermore, Sep is characterised by a high specific surface area and good surface affinity towards organic and inorganic species (Kadir and Akbulut, 2003; Sabah and Çelik, 2005; Suarez et al., 2016).
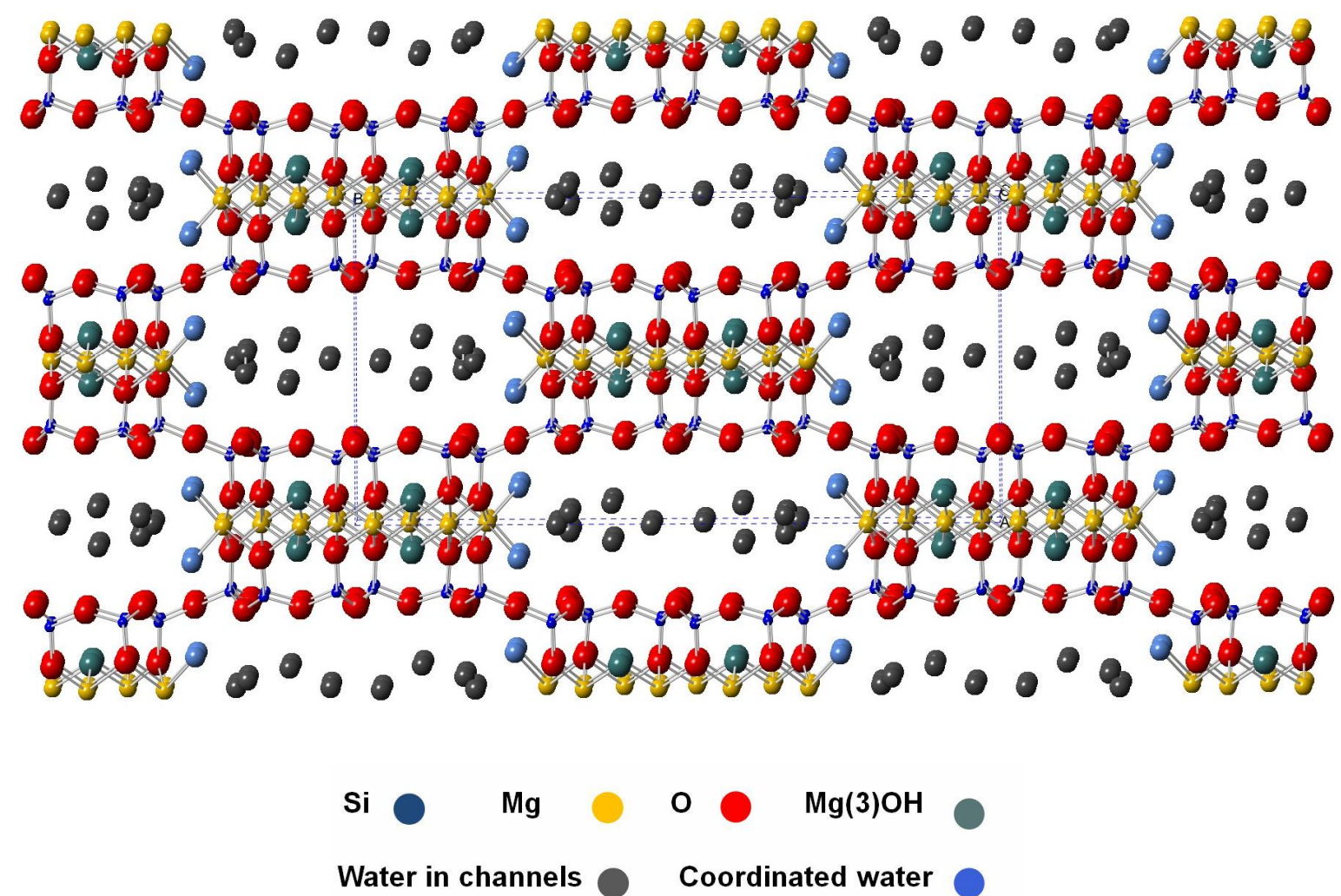

Fig. 1. Sepiolite structure (the blue dotted line indicates the unit cell size).

There has been a great deal of interest in utilising the sorptive, rheological and catalytic properties of Sep in many industrial applications (Alvarez, 1984). For instance, Sep has been recently used as catalyst support for green chemistry applications (Figen et al., 2018). Furthermore, a number of studies have been focused on the applications of natural clay minerals including Sep, red mud and bentonite as catalysts for the production of renewable fuels. Alves et al. (2014) utilised treated 
smectite clay with potassium fluoride in transesterification of soybean oil utilising the clay as a solid catalyst. Soetaredjo et al. (2011) examined the performance of potassium hydroxide impregnated bentonite as a catalyst for palm oil conversion. Agustain et al. (2012) used three metal (Ba, K and $\mathrm{Na}$ ) hydroxides supported on bentonite as catalysts for methanolysis of jatropha curcas oil. Degirmenbasi et al. (2014) used $\mathrm{K}_{2} \mathrm{CO}_{3}$ loaded Sep as a solid catalyst in transesterification of canola oil. Xu et al. (2013) employed red mud containing strongly basic active sites on the surface as a catalyst for biodiesel production from soybean oil. Most authors reported a high yield of FAMEs, typically over $90 \%$, after several hours of the reaction time at temperatures above $65^{\circ} \mathrm{C}$.

Important problems for heterogeneous systems, which can affect the catalytic performance, are structural integrity, thermal stability and the loss of active phases from the catalyst. A considerable challenge in an industrial application is maintaining the high catalyst activity for a number of reaction and regeneration cycles. However, many published reports do not describe the structural characterisation of the clay based catalysts before and after the reaction studies, which are often limited to a very small number, if any, of the successive runs on regenerated catalysts.

In this paper, potassium hydroxide loaded Spanish Sep has been prepared via wet impregnation and ion-exchange, and then used for the production of biofuel from both non-edible and edible oils using microwave heating. The aim of the present study is twofold: to carry out a detailed structural characterisation of the Sep-based catalyst both before and after the reaction and to evaluate the structure - performance relationship in the transesterification reaction for the production of biofuel from renewable feedstock for sustainable and clean energy applications.

\section{Experimental}

The Spanish Sep (ACS reagent) was obtained from Sigma-Aldrich. Potassium hydroxide (86\%), methanol, sodium hydroxide (99\%) and n-heptane (analytical grade, $>99.99 \%$ ) were purchased from Fisher Scientific. The grapeseed oil was supplied by Now Solutions (USA), refined rapeseed oil was purchased from a local market and castor oil was obtained from Fisher Scientific. Methyl heptadecanoate (analytical GC standard, >99.99\%) was supplied by Sigma-Aldrich.

Two types of catalysts were prepared by impregnation (K-Sep-Imp) and ion-exchange (K-Sep-IE) procedures. These were characterised before and after the reaction using in situ variable-temperature X-ray diffraction (VT XRD), scanning electronic microscopy with energy-dispersive X-ray analysis (SEM-EDX), thermogravimetric analysis (TGA), nitrogen adsorption-desorption and in situ FTIR spectroscopy. Detailed procedures are provided in the Electronic Supplementary Material (ESM). 
Following the transesterification reaction (Figure S1), the catalysts were separated, rinsed with methanol, dried at $60^{\circ} \mathrm{C}$ and reactivated under the same conditions as prior to the initial reaction and utilised again. The same reaction conditions were used in four consecutive runs for the recycled catalysts.

\section{Results and discussion}

One of the most important characteristics of a working catalyst is its structural stability. This can be affected at different stages of the catalyst activation and regeneration or in the course of the reaction itself. The structural properties of the Sep-based catalysts were monitored by both in situ and ex situ XRD, FTIR and $\mathrm{N}_{2}$ adsorption. Figures 2 and S2 (ESM) present the VT-XRD patterns of the Sep and K-Sep-Imp recorded at different calcination temperatures. There are clear changes in the patterns of both materials recorded above $200^{\circ} \mathrm{C}$. For Sep in particular, the intensity of the 110 reflection at $7.48^{\circ}(1.18 \mathrm{~nm}$ d-value; a summary of the indexed XRD reflections is given in Table S2), which corresponds to the interlayer distance in the clay structure, decreased significantly, becoming negligible above $300^{\circ} \mathrm{C}$. Similar intensity changes were observed for the same reflection (1.19 nm d-value) in the patterns of the K-Sep-Imp sample. It is suggested that the layered structure of the catalyst collapsed during the high temperature calcination. The observed structural changes are not reversible as the VT-XRD patterns, recorded for both materials upon cooling, did not change. Our data are in accord with the findings of Preisinger (1959), Dany and Nadiye-Tabbiruka (1975) and Grillet et al. (1988) indicating that the Sep structure showed significant changes upon heating above $150^{\circ} \mathrm{C}$, which was accompanied by the loss of water and microporosity. In addition, an in situ variable-temperature synchrotron investigation (Post et al., 2007) and a number of ex situ studies (Kok, 2013; Pikkin, 2013; Yeniyol et al., 2014) on Sep samples calcined up to $900^{\circ} \mathrm{C}$ demonstrated the folding of the Sep structure resulting from its dehydration above $320^{\circ} \mathrm{C}$ with the loss of the micropore channels, which was followed by the formation of two "anhydrous" Sep phases at $~ 460$ and $650^{\circ} \mathrm{C}$. These results and most literature data, however, disagree with those presented by Degirmenbasi et al. (2014), who suggested that heating Sep to $500^{\circ} \mathrm{C}$ did not cause any change in the catalyst structure. Our nitrogen adsorption and TGA-DSC data support the VT-XRD finding. Indeed, the BET surface area $\left(\mathrm{S}_{\mathrm{BET}}\right)$ of Sep decreased with increasing activation temperature from 325 to 130 $\mathrm{m}^{2} / \mathrm{g}$ (Figures 3, 4 and S3, ESM); the BET surface area of K-Sep-Imp was below $100 \mathrm{~m}^{2} / \mathrm{g}$. Therefore nitrogen adsorption and XRD data clearly demonstrate that potassium introduction and activation at elevated temperatures lead to considerable structural degradation and a significant decrease in the $\mathrm{S}_{\mathrm{BET}}$. In addition, the micropores present in the original Sep ( $\sim 0.8 \mathrm{~nm}$ in diameter) in the spaces between the silicate layers were no longer detected for the samples activated at temperatures above $200^{\circ} \mathrm{C}$. These results are also supported by previous research (Gómez-Avilés et 
al., 2013; Pikkin et al., 2013; Pozo et al., 2014; Suarez et al., 2016). While these publications did confirm the high surface area of Sep and indicate the presence of micropores, to the best of our knowledge, our work is the first to present a detailed characterisation of a series of thermally treated Sep samples in the region of low $\mathrm{P} / \mathrm{P}_{\mathrm{o}}$ values corresponding to the micropore filling by nitrogen.

(a)

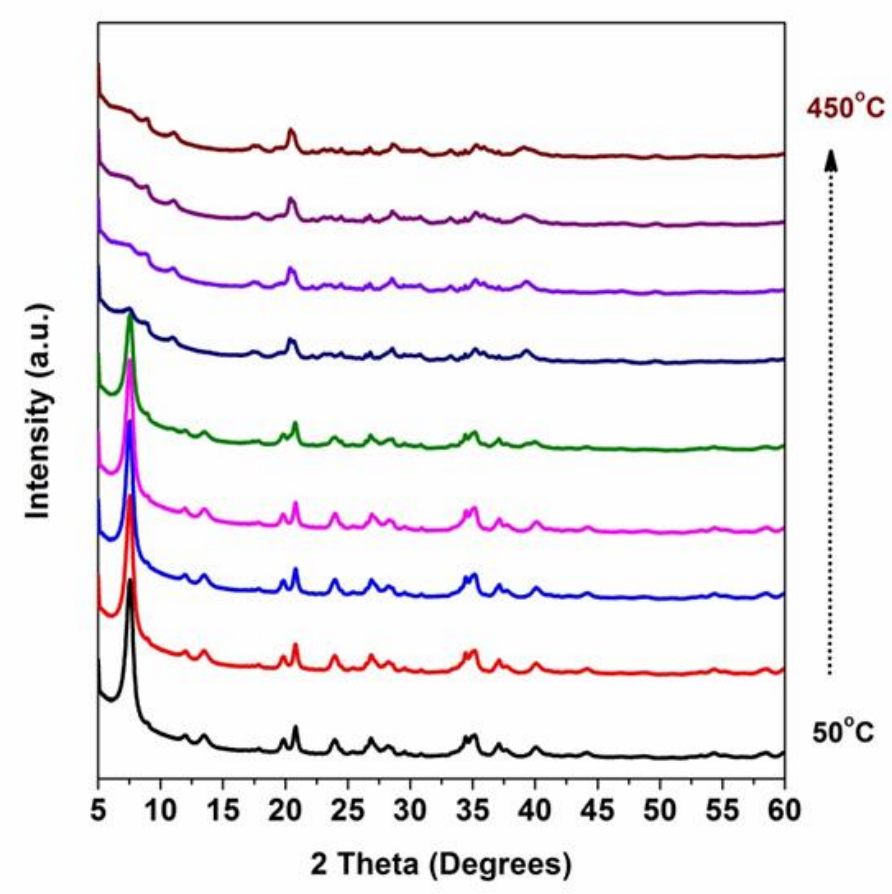

(b)

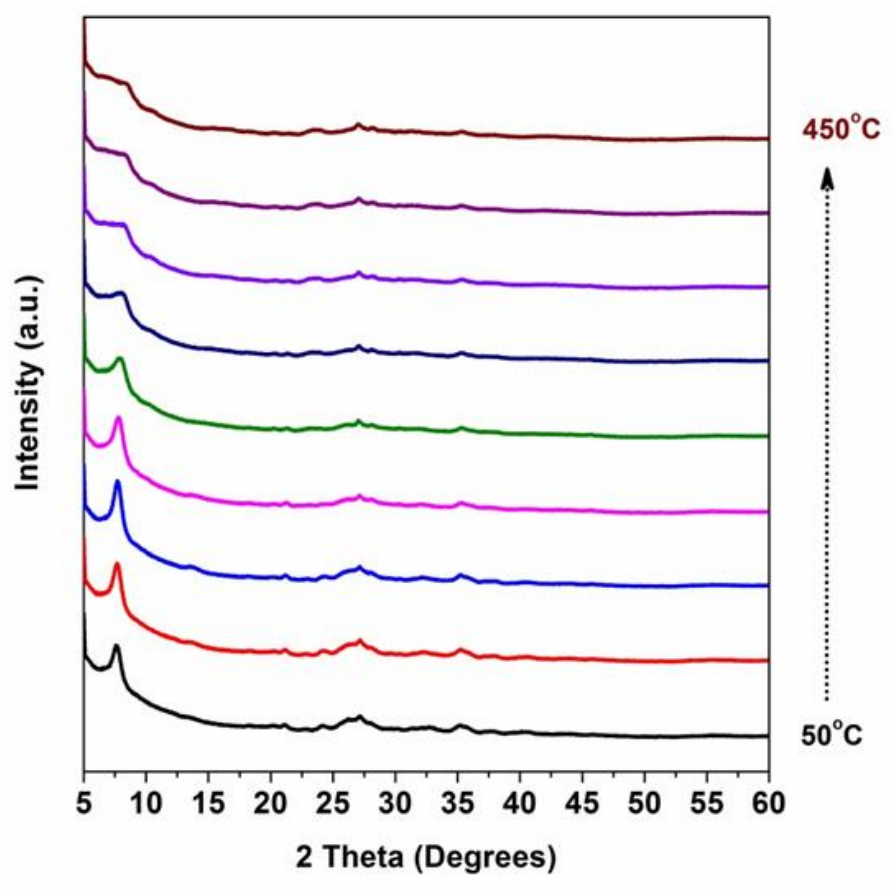

Fig. 2. In situ VT XRD patterns collected every $50^{\circ} \mathrm{C}$ (heating up) of (a) parent Sep catalyst and (b) K-Sep-Imp. Patterns are offset for clarity. 
(a)

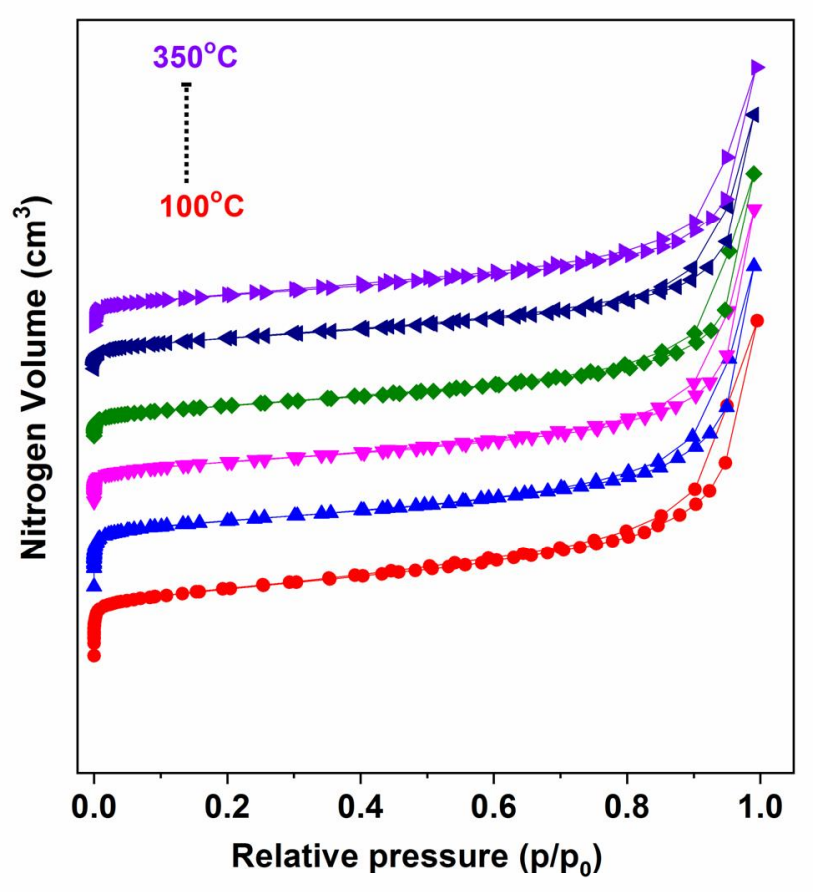

(b)

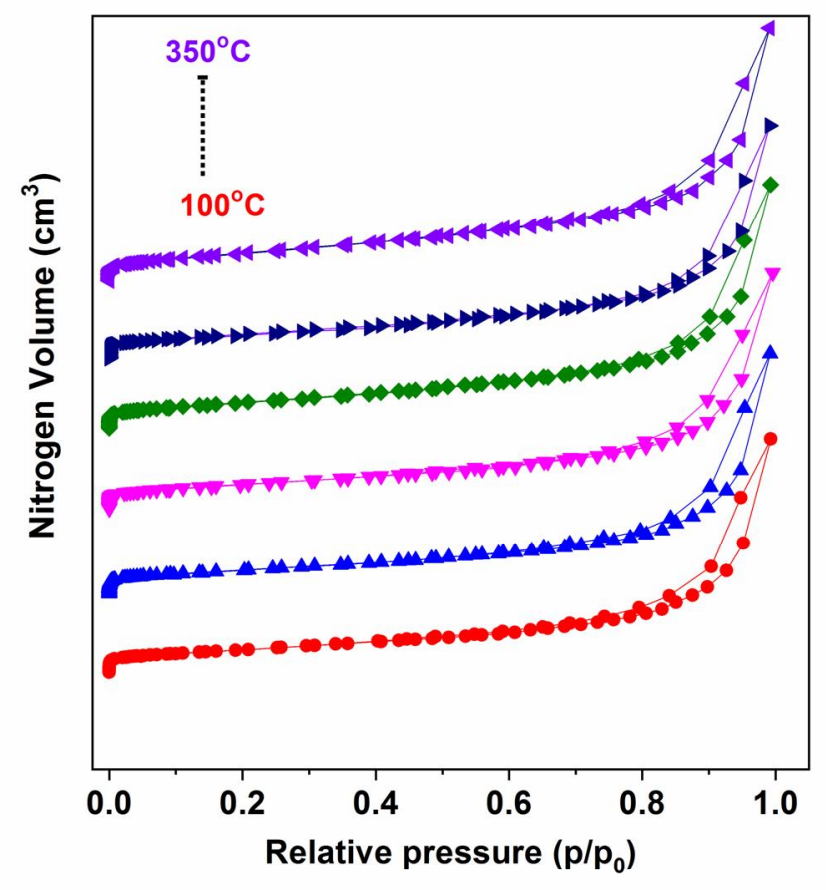

Fig. 3. Nitrogen adsorption isotherms for (a) Sep and (b) K-Sep-Imp activated at $100-350^{\circ} \mathrm{C}$ in $50^{\circ} \mathrm{C}$ steps. Isotherm traces are offset for clarity. 
(a)

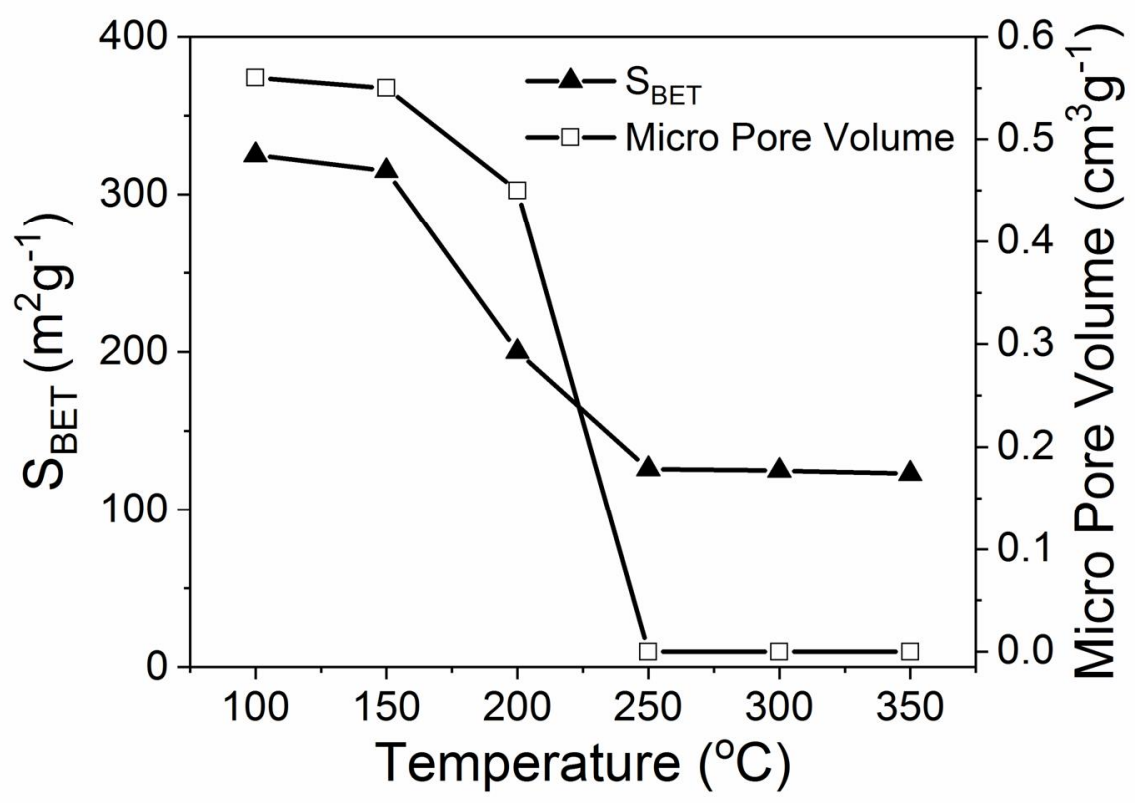

(b)

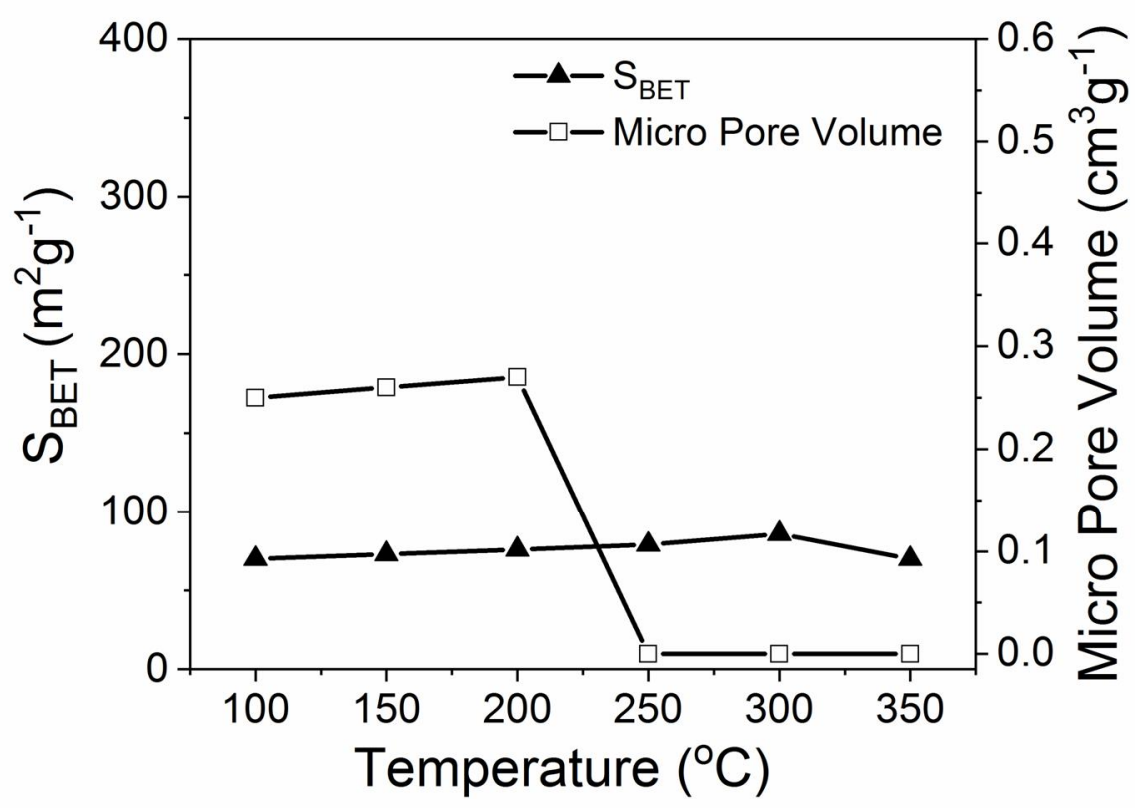

Fig. 4. Specific surface area and micropore volume data as a function of the activation temperature for (a) Sep and (b) K-Sep-Imp.

151 Although the thermal treatment process is essential for the decomposition of the metal precursor, 152 there is a significant change in the catalyst properties caused by heating above $250^{\circ} \mathrm{C}$, which is 153 associated with the loss of water and the collapse of the layered structure. In agreement with 154 previous studies (Hayashi et al., 1969; Kok, 2013; Ogorodova et al., 2016), our TGA-DSC data 155 confirmed the stepwise removal of water from Sep, which accounts for $\sim 9 \%$ of the mass loss at $156100^{\circ} \mathrm{C}$ and $\sim 4 \%$ at $250-300^{\circ} \mathrm{C}$ (both steps are endothermic processes as expected) with the total mass 
157 loss of $\sim 18 \%$ by $900^{\circ} \mathrm{C}$ (Figure 5). The exothermic peak observed at $850^{\circ} \mathrm{C}$ corresponds to a high 158 temperature phase transition resulting in a complete loss of the Sep structure. The data obtained for 159 K-Sep were largely similar, $\sim 15 \%$ of the mass loss at $400^{\circ} \mathrm{C}$ and $\sim 18 \%$ by $900^{\circ} \mathrm{C}$, but showing a 160 more gradual removal of water from this material as compared to the parent Sep sample (Hayashi et 161 al.,1969).

(a)

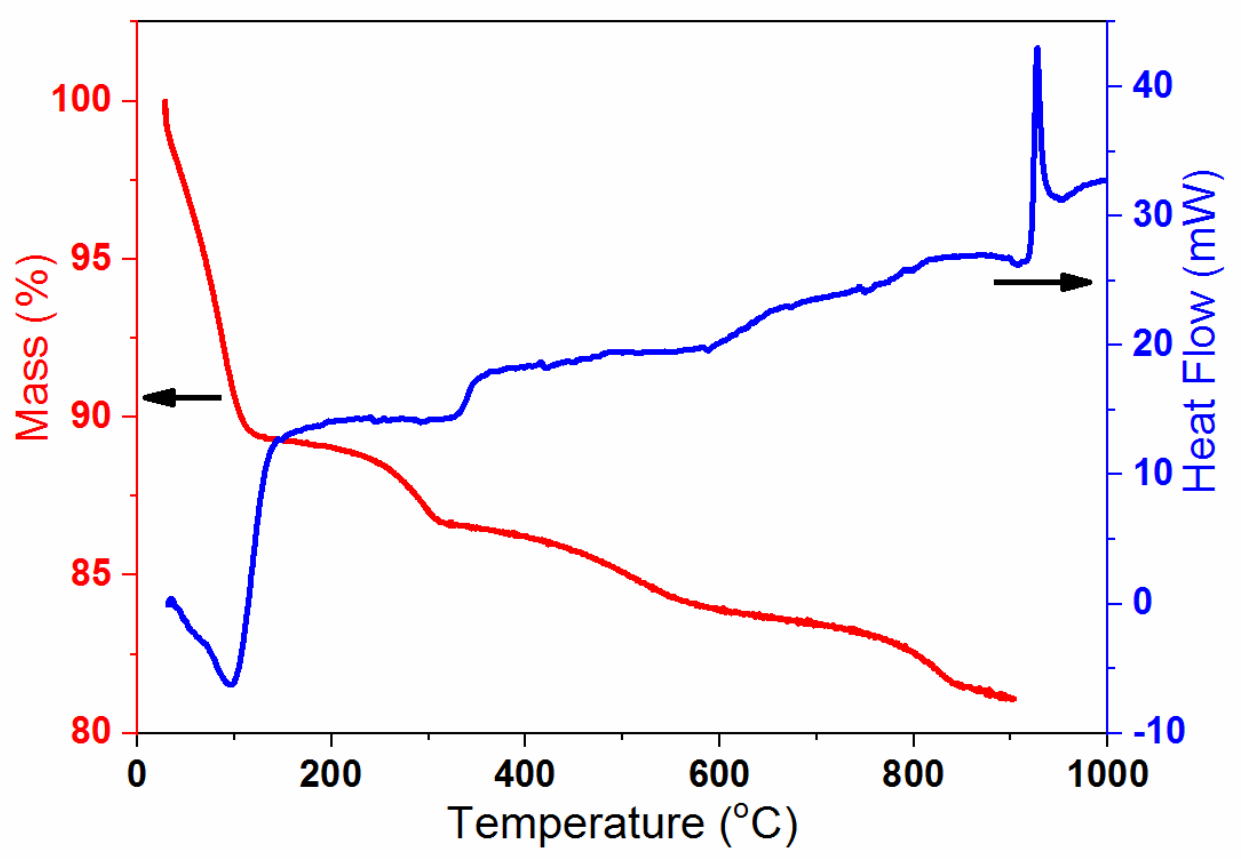

(b)

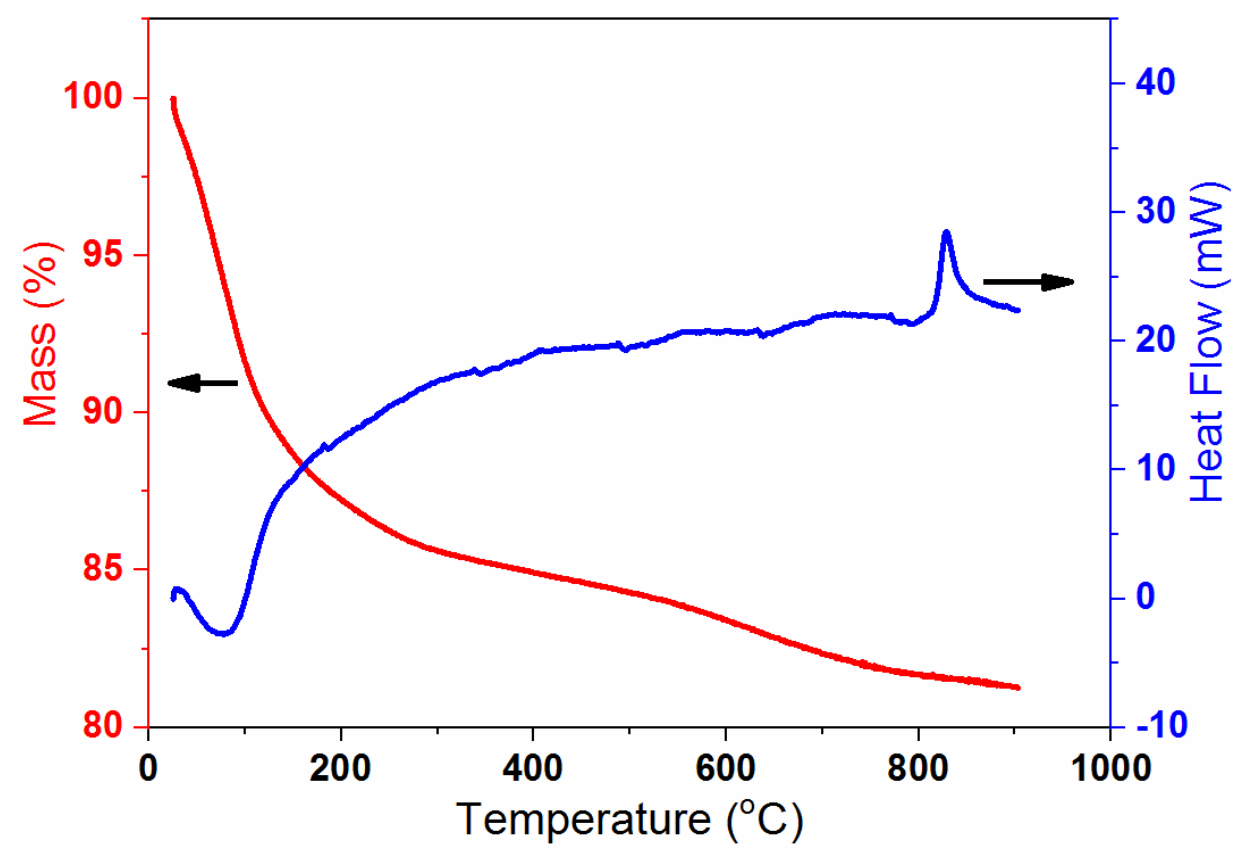

Fig. 5. Thermogravimetric analysis data for (a) Sep and (b) K-Sep. 


\begin{tabular}{|c|c|c|c|c|c|c|}
\hline \multirow[t]{2}{*}{ Material } & \multicolumn{4}{|c|}{$\begin{array}{c}\text { Elemental composition } \\
(w t \%)\end{array}$} & \multirow[t]{2}{*}{$\begin{array}{c}S_{B E T} \\
\left(m^{2} / g\right)^{a}\end{array}$} & \multirow[t]{2}{*}{$\begin{array}{r}V_{\text {micro }} \\
\left(\mathrm{cm}^{3} / \mathrm{g}\right)^{\prime}\end{array}$} \\
\hline & Silicon & Magnesium & Potassium & Sodium & & \\
\hline Parent Sep & 22.5 & 13.3 & $<0.2$ & - & 195 & 0.39 \\
\hline K-Sep-Imp & 17.3 & 13.4 & 6.1 & - & 75 & 0.27 \\
\hline K-Sep-Imp used & 17.2 & 13.3 & 3.2 & - & 70 & 0.01 \\
\hline K-Sep-IE & 19.7 & 11.8 & 4.0 & 4.6 & 85 & 0.28 \\
\hline K-Sep-IE used & 19.8 & 12.0 & 2.5 & 1.8 & 80 & 0.01 \\
\hline
\end{tabular}


(a)

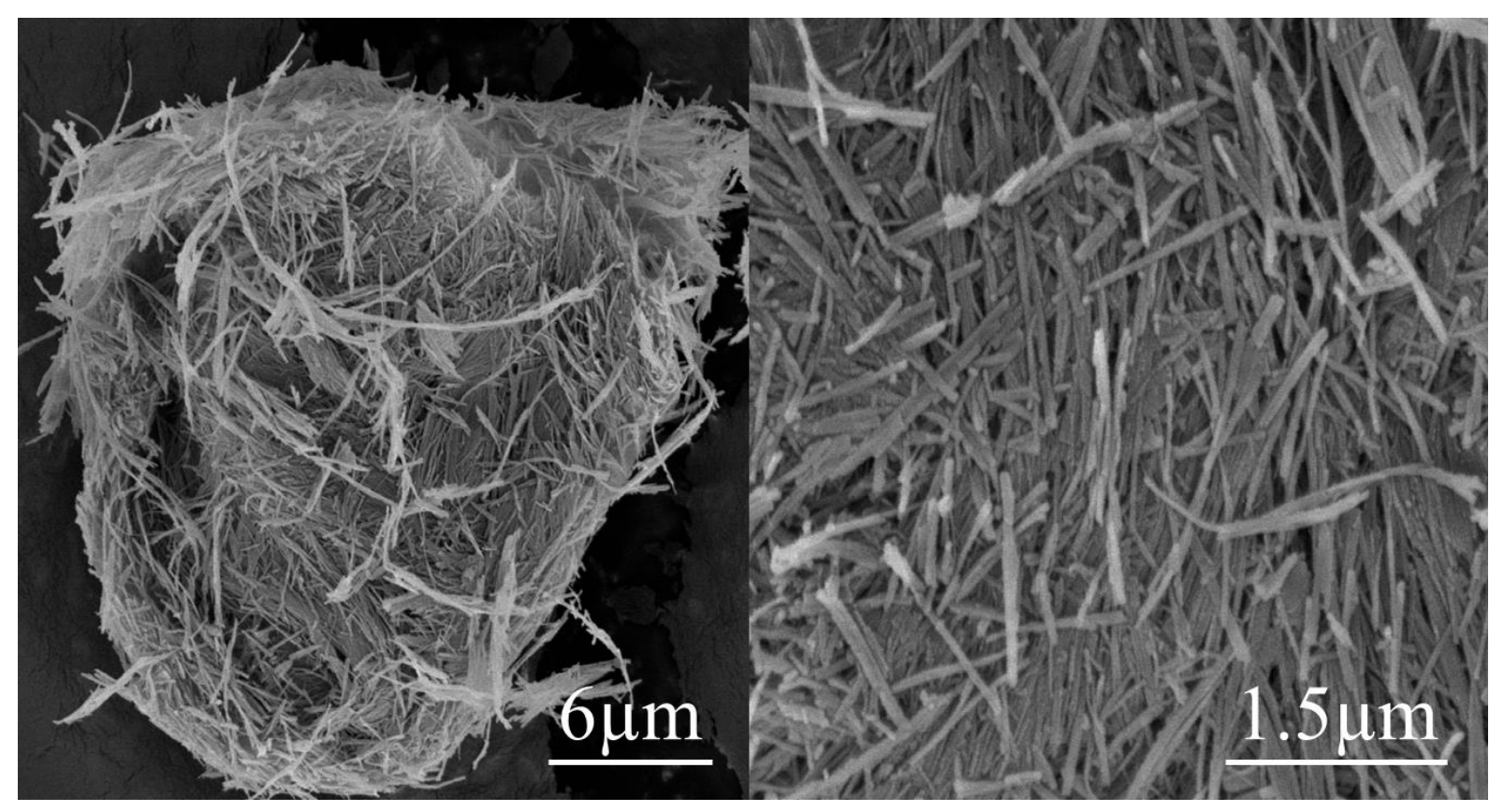

(b)

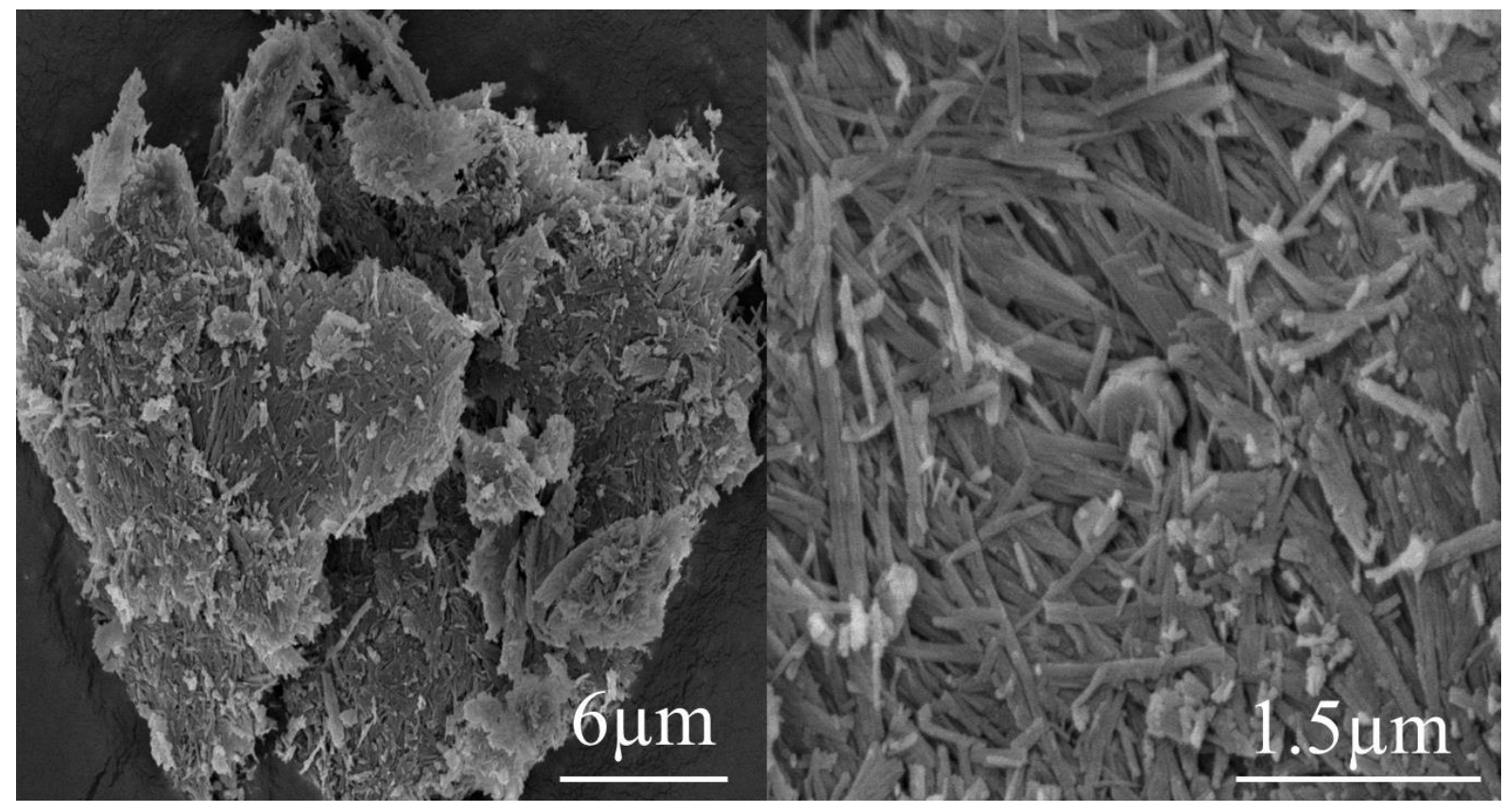


(c)

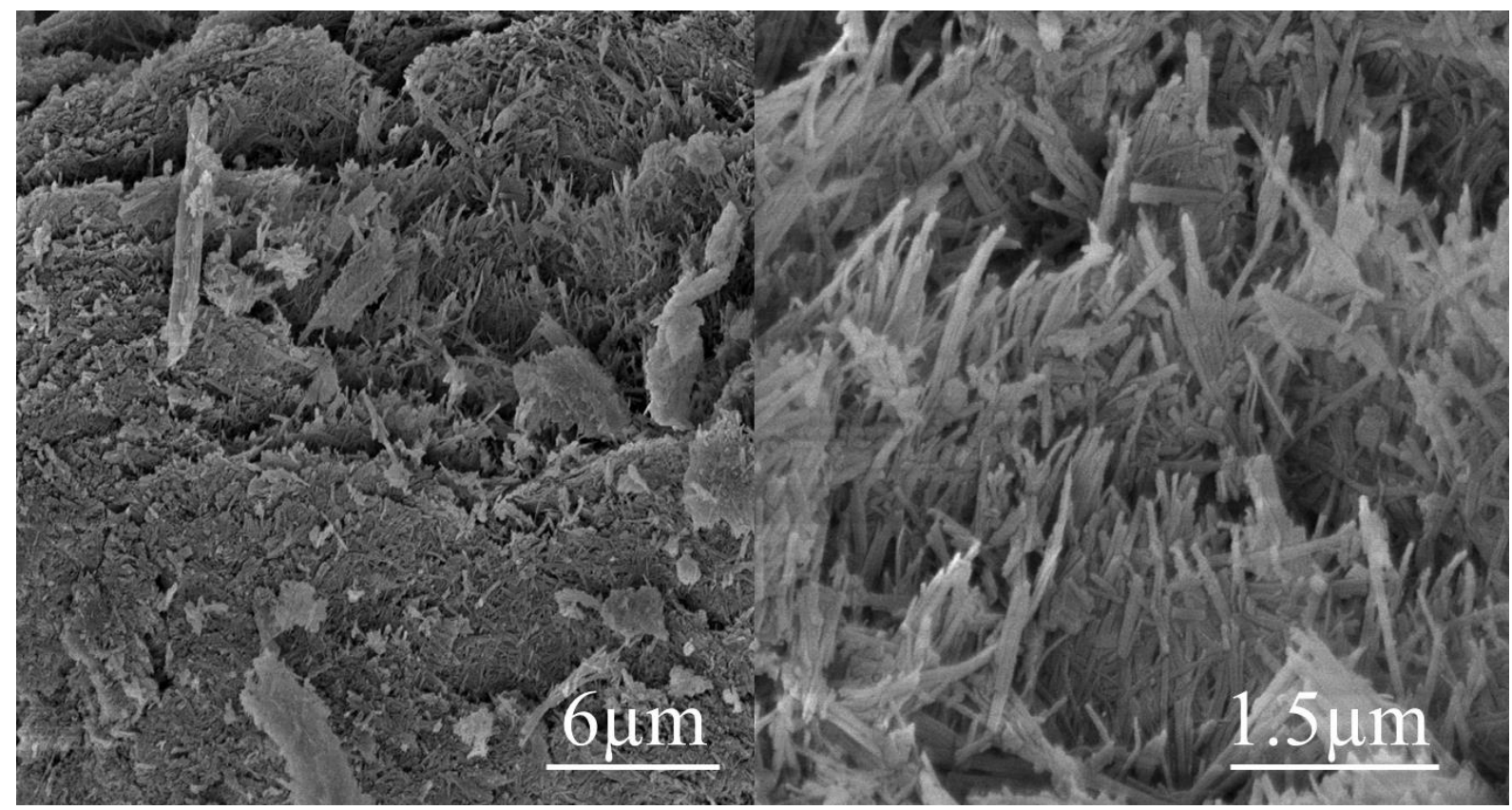

Fig. 6. SEM images of (a) Sep, (b) K-Sep-Imp and (c) K-Sep-Imp following reaction and regeneration. 
(a)

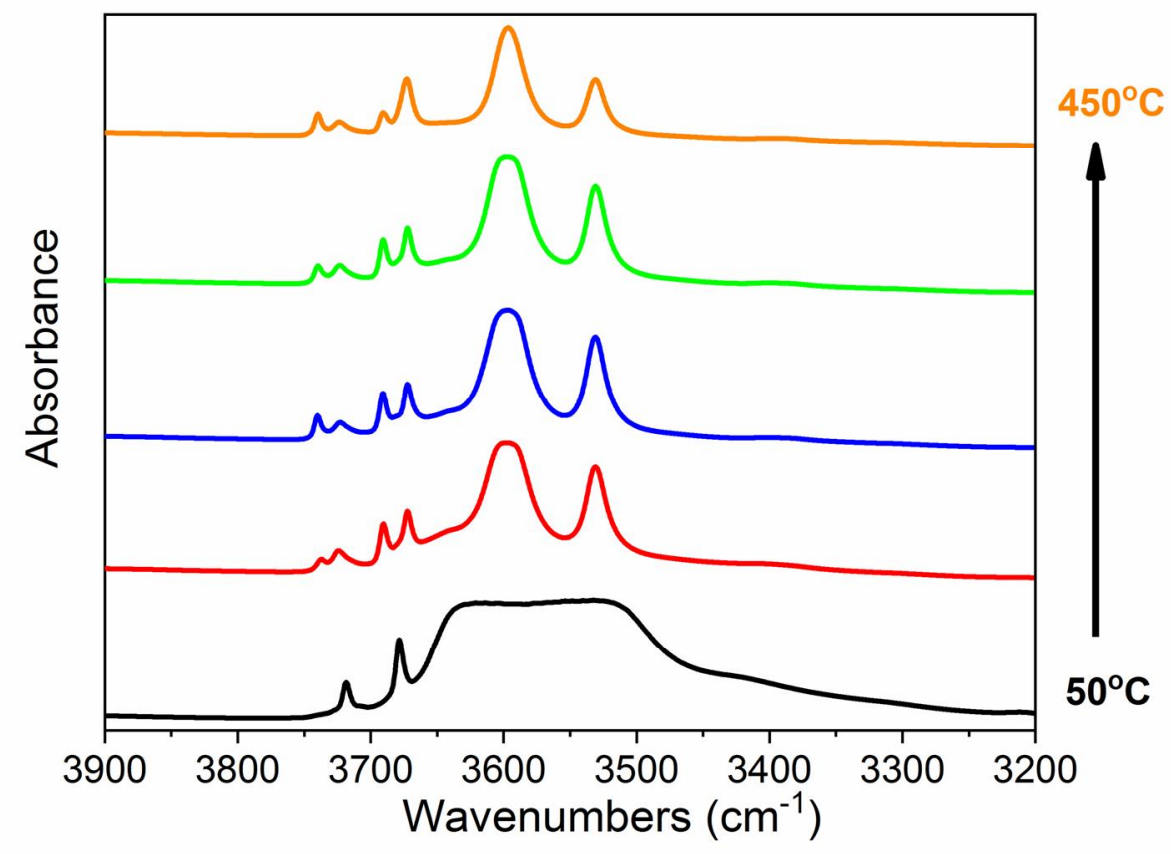

(b)

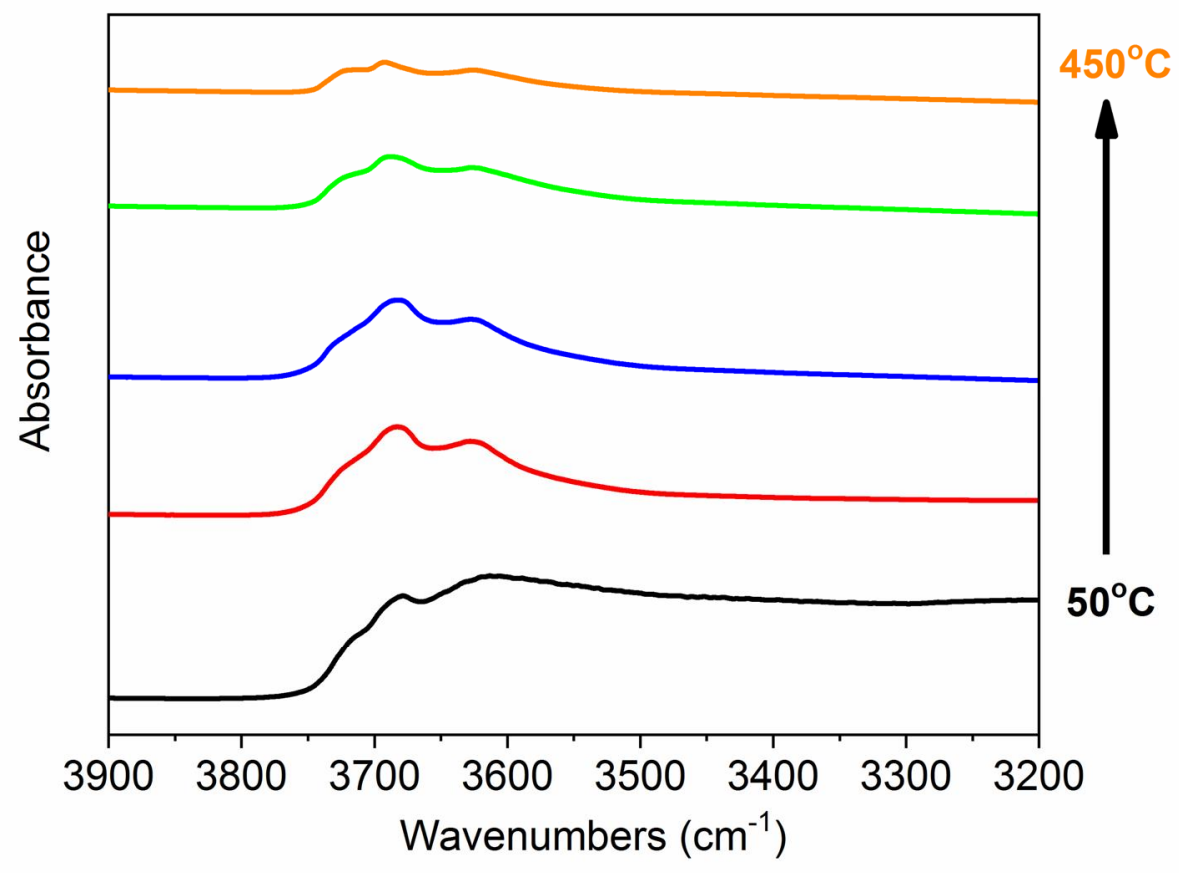

Fig. 7. The OH-region of FTIR spectra for (a) Sep and (b) K-Sep-Imp catalysts activated at $50-450^{\circ} \mathrm{C}$ in $100^{\circ} \mathrm{C}$ steps. Spectra are offset for clarity. 
185

186

187

188

189

190

191

192

193

194

195

196

197

198

199

200

201

202

203

204

205

206

207

208

209

210

211

212

213

214

215

216

217

The OH region of the FTIR spectra for Sep and K-Sep-Imp are presented in Figure 7 (the wide range spectra, from 1000 to $6000 \mathrm{~cm}^{-1}$ including the overtones and combination frequencies, are available in ESM, Figure S4). The evolution of the spectral bands of different types of OH groups was followed in situ during sample dehydration between 30 and $450^{\circ} \mathrm{C}$. The initial spectra were dominated by the broad feature at $\sim 3650-3300 \mathrm{~cm}^{-1}$ owing to weakly bound water molecules, which are commonly referred to as "zeolitic water" in the mineralogical literature, and which were removed upon mild dehydration at $150^{\circ} \mathrm{C}$. Two overlapping bands at 1625 and $1616 \mathrm{~cm}^{-1}$ were also observed in the region of $\mathrm{OH}-$ bending vibrations. The spectra of the dehydrated samples exhibited six peaks in the region of stretching O-H vibrations. In agreement with the literature (Hayashi et al., 1969; Frost et al., 2001; Ruiz et al., 2010; Giustetto et al., 2010; Bukas et al., 2013; Post et al., 2014; Chryssikos et al., 2015), the peaks at 3740 and $3724 \mathrm{~cm}^{-1}$ are assigned to Si-OH groups of the tetrahedral silicate layer and those at 3691 and $3673 \mathrm{~cm}^{-1}$ to $\mathrm{Mg}(3)-\mathrm{OH}$ groups in the octahedral sheets of the Sep structure. The bands at 3597 and $3531 \mathrm{~cm}^{-1}$ are attributed to water molecules coordinated to $\mathrm{Mg}$ cations, which is supported by the presence of a single band at $1616 \mathrm{~cm}^{-1}$ in the region of bending $\mathrm{OH}$ vibrations. Interestingly, these peaks persisted in the spectra of the samples dehydrated in vacuum at $450^{\circ} \mathrm{C}$ for 5 hours. It should be noted that there are minor variations in the position of the absorption bands reported in the literature, which is probably related to the fact that most of the previous data were obtained using ex situ experiments on calcined samples or $\mathrm{KBr}$ disks with somewhat uncertain degree of control over the hydration and dehydration processes. Although the interpretation of the spectra has been supported by extensive NIR characterisation of Sep (Frost et al., 2001; Ruiz et al., 2010; Giustetto et al., 2010; Chryssikos et al., 2015), a different assignment could not be completely ruled out. For instance, two $\mathrm{OH}$ bands at 3734 and $3583 \mathrm{~cm}^{-1}$ were observed in the spectra of magnesium oxide calcined at $500^{\circ} \mathrm{C}$ (Hadjiivanov, 2014). The spectra of K-Sep dehydrated at elevated temperatures displayed rather broad overlapping bands between 3750 and $3600 \mathrm{~cm}^{-1}$. This is in agreement with our VT-XRD and nitrogen adsorption data indicating considerable structural degradation upon $\mathrm{KOH}$ impregnation and calcination of this material.

The structural stability, high surface area and strong bonding with the active phase preventing the loss of the active sites are essential characteristics of a supported catalyst (Romero et al, 2016). Figure 8 presents a comparison of the catalytic performance of K-Sep-Imp in transesterification of triglycerides over several reactions $\ddot{i}$ regeneration cycles. These data demonstrate a significant deactivation of K-Sep-Imp, which can be linked to its structural integrity and loss of the active sites. Although we obtained high yield and selectivity of FAMEs in the presence of K-Sep-Imp and KSep-IE, these materials lack long-term stability in the methanolysis reaction. A considerable change 
in the catalyst structure was found after calcination at elevated temperatures, accompanied by the loss of water and a significant reduction in its surface area. In contrast to our results and the data available in the literature, Degirmenbasi et al. (2014) concluded that a higher catalytic activity of Sep impregnated with $\mathrm{K}_{2} \mathrm{CO}_{3}$ in the transesterification of canola oil is achieved following its calcination to $500^{\circ} \mathrm{C}$, apparently resulting in a catalyst more resistant toward the leaching of the active phase. However, our structural characterisation, chemical analysis and catalytic data for the Sep-based catalysts that were calcined or regenerated at temperatures between 250 and $450^{\circ} \mathrm{C}$ provide no evidence of enhanced catalytic performance or improved structural stability following the high temperature treatment. In addition, characterisation of the regenerated catalysts demonstrated that the $\mathrm{K}^{+}$ions were leaching out during the transesterification reaction or the regeneration step, which was accompanied with a significant drop in the yield of FAMEs in the subsequent catalytic run from $100 \%$ to $78 \%$. A similar drop in activity was observed for the K-Sep-IE.

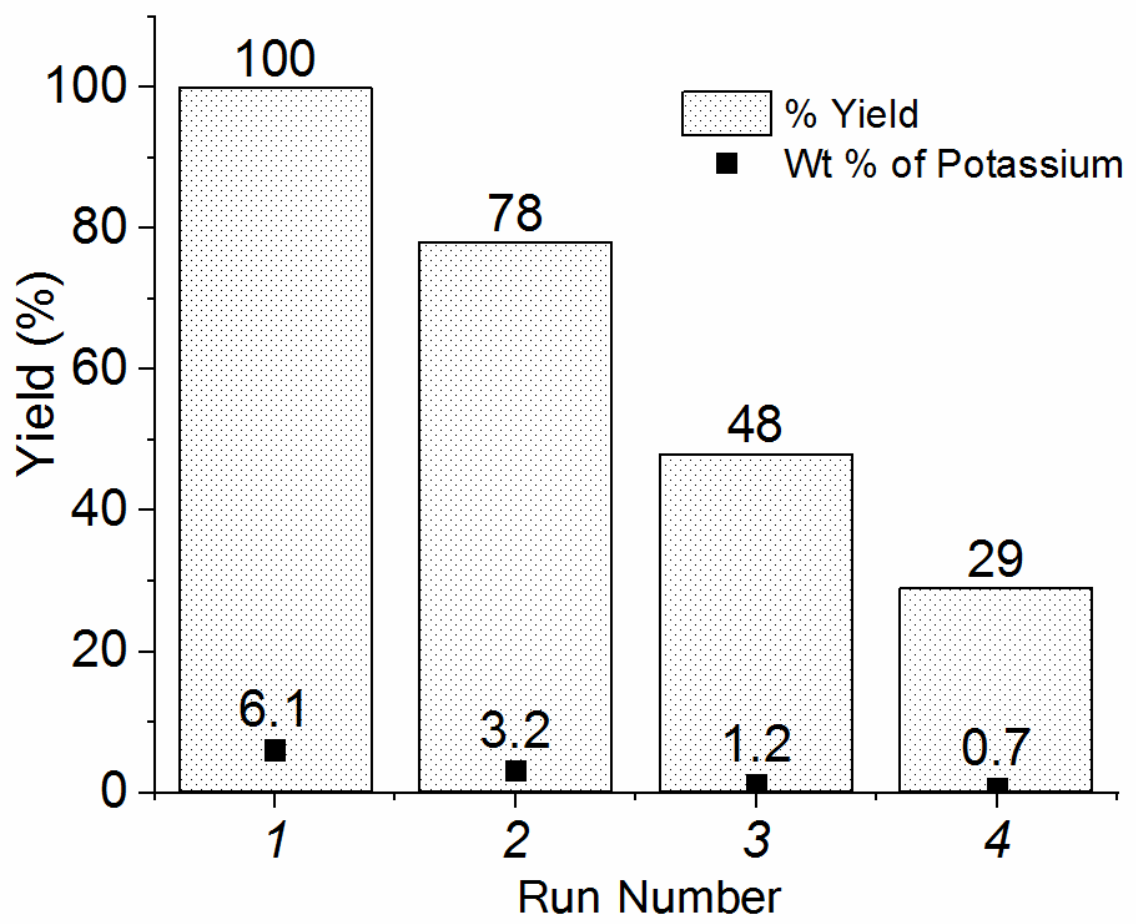

Fig. 8. Catalytic performance of the fresh and used K-Sep-Imp in the transesterification of grapeseed oil at $160^{\circ} \mathrm{C}$ and the wt $\%$ of potassium in these catalysts.

Furthermore, in a blank reaction run with $0.0035 \mathrm{~g}$ of $\mathrm{KOH}$ (approximately the amount of potassium hydroxide lost by K-Sep-Imp in the first reaction cycle), a triglyceride conversion of $\sim 75 \%$ was observed, confirming that potassium hydroxide in solution was active in the transesterification reaction. Clearly, such effects should be taken into account, considering a significant number of 
studies utilising clay-based catalysts either impregnated or ion-exchanged with potassium containing compounds (Corma and Martin-Aranda, 1991; Villamiel et al., 2002; Ilgen and Akin, 2012; Degirmenbasi et al., 2013, 2014; Chryssikos et al., 2015; Wang et al., 2017).

\section{Conclusion}

The application of heterogeneous catalysts in the production of biodiesel offers potential advantages including lower cost, high stability and the ease of separation. In this work, Sep modified with Kbearing compounds was prepared using impregnation and ion exchange procedures. The evolution of the structural features of these catalysts was characterised in detail both before and after the reaction by variable-temperature in situ XRD, $\mathrm{N}_{2}$ adsorption-desorption, SEM-EDX and in situ FTIR spectroscopy in order to evaluate their structure - performance relationship in the methanolysis of vegetable oils. Our data demonstrated that the Sep structure undergoes irreversible changes upon heating above $250^{\circ} \mathrm{C}$, which are accompanied by the loss of water and $\mathrm{OH}$ groups. High-temperature calcination resulted in dehydration of Sep followed by the folding of its structure with the loss of the micropore channels and significant decrease in the surface area. Sep impregnation with KOH also led to partial structural degradation and decrease in the surface area. Subsequent thermal treatment, required for the decomposition of the metal precursor with the formation of an oxide on the Sep support, can cause further structural changes associated with dehydration and the collapse of the layered structure. Although high yield of FAMEs was obtained in transesterification in the presence of K-Sep, our work demonstrated that both impregnated and ion-exchanged K-Sep lack long-term stability in this reaction due to the loss of the active component during the recycling stages. Overall, our reaction studies and extensive structural analysis point to a potentially significant contribution of the homogeneously catalysed transformation of triglycerides in the presence of clay-based catalysts.

\section{Acknowledgments}

This work was supported by Ministry of Oil /Oil Marketing Company (SOMO), Baghdad, Iraq under grant SL-144-01B. The authors appreciate the support of the Lennard-Jones Laboratories and the School of Geography, Geology and the Environment at Keele University, UK, where this study was carried out. We thank Karen Walker of Keele University for her help with obtaining SEM images. 


\section{References}

Agustian, E., Ghozali, M., Savitri, R., Wuryaningsih, S., 2012. Biodiesel production of jatropha curcas oil by bentonite as catalyst, Proceeding of International Conference on Sustainable Energy Engineering and Application, 35-39.

Alvarez, A., 1984. Sepiolite: properties and uses. Developments in Sedimentology. 37, 253-287.

Alves, H.J., da Rocha, A.M., Monteiro, M.R., Moretti, C., Cabrelon, M.D., Schwengber, C.A., Milinsk, M.C., 2014. Treatment of clay with KF: New solid catalyst for biodiesel production. Appl. Clay Sci. 91, 98-104.

Armenteros, I, Bustillo M.A.A., Blanco J.A. 1995. Pedogenic and groundwater processes in a closed Miocene basin (northern Spain). Sed. Geol. 99, 17-36.

Bukas, V.J., Tsampodimou, M., Gionis, V., Chryssikos, G.D., 2013. Synchronous ATR infrared and NIR-spectroscopy investigation of sepiolite upon drying. Vib. Spect. 68, 51-60.

Bustillo, M.A., Alonso-Zarza, A.M., 2007. Overlapping of pedogenesis and meteoric diagenesis in distal alluvial and shallow lacustrine deposits in the Madrid Miocene Basin, Spain. Sed. Geol. 198, 255-271.

Chryssikos, G.D.,Tsampodimou, M., Bukas, V., Stathopoulou, E.T., Gionis, V.,2015. Near-infrared investigation of folding sepiolite. Am. Miner. 100(1), 195-202.

Corma, A., Martin-Aranda, R.M., 1991. Alkaline-substituted sepiolites as a new type of strong base catalyst. J. Cata. 130(1), 130-137.

Corma, A., Huber, G.W., Iborra, S., 2006. Synthesis of transportation fuels from biomass: [themistry, catalysts, and engineering. Chem. Rev. 106 (9), 4044-4098.

Dandy, A., Nadiye-Tabbiruka, M., 1975, The effect of heating in vacuo on the microporsity of sepiolite. Clays Clay Miner. 23, 428430.

Deer, W.A., Howie, R.A., Zussman, J., 1992. An Introduction to the Rock-Forming Minerals. Prentice Hall ( $2^{\text {nd }}$ edition); pp. 712.

Degirmenbasi, N. Boz, N., Kalyon, D.M., 2013. Transesterification of canola oil to biodiesel using calcium bentonite functionalized with K compounds. Appl. Catal. B: Envir. 138ї 139, 236-242.

Degirmenbasi, N., Boz, N., Kalyon, D.M., 2014. Biofuel production via transesterification using sepiolite-supported alkaline catalysts. Appl. Catal. B: Envir. 150,147-156.

Ehlmann, A.J., Sand, L.B., Regis, A.J., 1962. Occurrences of sepiolite in Utah and Nevada. Econ. Geol. 57, 1085-1094.

Figen, A.K., Meke, E., Filiz, B.C., Pikkin, S., 2018. Cobalt-boron loaded thermal activated Turkish sepiolite composites (Co-B@ tSe) as a catalyst for hydrogen delivery. Appl. Clay Sci. 153, 95-106.

Frost, R.L., Locos O.B., Ruan, H., Kloprogge, J.T., 2001. Near-infrared and mid-infrared spectroscopic study of sepiolites and palygorskites. Vib. Spect. 27 (1), 1-13. 
Galán, E., Castillo, A., 1984. Sepiolite-palygorskite in Spanish Tertiary basins: genetical patterns in continental environments. Developments in Sedimentology 37, 87-124.

Galán, E., Ferrero, A., 1982. Palygorskite-sepiolite clays of Lebrija, Southern Spain. Clays and Clay Minerals 30, 191-199.

Gandía, L.M., Navajas, A., Campo, I., Moral, A., Echave, J., Sanz, O., Montes, M.,Odriozola, J.A., Arzamendi, G., 2018. Outstanding performance of rehydrated Mg-Al hydrotalcites as heterogeneous methanolysis catalysts for the synthesis of biodiesel. Fuel. 211, 173-181.

Gedanken, A., Tangy, A., Pulidindi, I.N., 2016. $\mathrm{SiO}_{2}$ beads decorated with $\mathrm{SrO}$ nanoparticles for biodiesel production from waste cooking oil using microwave irradiation. Energy \& Fuels 30(4), 3151-3160.

Giustetto, P., Seenivasan, K., Bordiga, S., 2010. Spectroscopic characterization of a sepiolite-based Maya Blue pigment. Periodicodi Mineralogia. 21-37.

Gómez-Avilés, A.,Aranda, P.,Fernandes, F.M., Belver, C., Ruiz-Hitzky, E., 2013. Silica-sepiolite nanoarchitectures. J Nanosci Nanotechnol. 13 (4), 2897-2907.

Grillet, Y., Cases, J., Francois, M., Rouquerol, J. \& Poirier, J. 1988. Modification of the porous structure and surface area of sepiolite under vacuum thermal treatment. Clays Clay Miner. 36, 233242.

Hadjiivanov, K., 2014. Identification and characterization of surface hydroxyl groups by infrared spectroscopy. Adv. Catal. 57, 99-318.

Hayashi, H., Otsuka, R., Imai, N.,1969. Infrared study of sepiolite and palygorskite on heating. Am. Min. 53, 1613-1624.

Ilgen, O., Akin, A.N., 2012. Determination of reaction orders for the transesterification of canola oil with methanol by using $\mathrm{KOH} / \mathrm{MgO}$ as a heterogeneous catalyst. Appl. Catal. B: Envir. 126, 342-346.

Irkeç, T., Unlu, T.,1993. An example of sepiolite formation in volcanic belts by hydrothermal alteration: Kibriscik (Bolu) sepiolite occurrence. Mineral Res. Exploration Bull. 115, 49-68.

Kadir, S., Akbutut, A., 2003. The geology and origin of sepiolite, palygorskite and saponite in Neogene lacustrine sediments of the Serinhisar-Acipayam Basin, Denizli, SW Turkey Clays Clay Miner.51, 279-292.

Kadir, S., Erkoyun, H., Eren, M., Huggett, J., Önalgil, N., 2016. Mineralogy, geochemistry, and genesis od sepiolite and palygorskite in Neogene lacustrine sediments, Eskikehir Province, West Central Anatolia, Turkey. Clays and Clay Minerals 64 (2), $145 \mathrm{ï} 166$.

Kok, M.V., 2013. Thermal characterization of sepiolite samples Energy Sources, Part A: Recovery, Utilization, and Environmental Effects 35 (2),173-183.

Leguey, S., Ruiz de Leon, D., Ruiz, A.I., Cuevas, J., 2010. The role of biomineralization in the origin of sepiolite and dolomite. American Journal of Science 310, 165-193. 
Mota, C.J.A., de Lima, A.L., Ronconi, C.M., 2016. Heterogeneous basic catalysts for biodiesel production. Cata. Sci. \& Technol. 6 (9), 2877-2891.

Ogorodova, L.P, Vigasina, M.F., Melchakova, L.V., Kiseleva, I.A., Krupskaya, V.V., Bryzgalov, I.A., 2016. Natural Mg-Fe clinochlores: enthalpies of formation and dehydroxylation derived from calorimetric study. Am. Miner. 101(6), 1431-1437.

Pikkin, S., Yđ̊maz, M.S., Kalpaklē Y., 2013. Thermal behavior and dehydroxylation kinetics of naturally occurring sepiolite and bentonite. J. Ther. Anal. Calor. 114(3), 1191-1199.

Post, J.E., Bish, D.L., Heaney, P.J., 2007. Synchrotron powder X-ray diffraction study of the structure and dehydration behavior of sepiolite. Am. Miner. 92 (1),91-97.

Post, J.L.,Crawford, S.M., 2014.Uses of near-infared spectra for the identification of clay mineralsAppl. Clay Sci. 95,383-387.

Pozo, M., Calvo, J.P., Pozo, E., Moreno, Á., 2014. Genetic constraints on crystallinity, thermal behaviour and surface area of sepiolite from the Cerro de los Batallones deposit (Madrid Basin, Spain). Appl. Clay Sci. 91-92, 30-45.

Preisingei, A., 1959. X-ray study of the structure of sepiolite. Clays Clay Miner. 6, 61-67.

Romero, R., Muciño, G.E.G., Garcia-Orozco, I., Serrano, A.R., Jiménez, R.B., Natividad, R., 2016. Deactivation study of $\mathrm{K}_{2} \mathrm{O} / \mathrm{NaX}$ and $\mathrm{Na}_{2} \mathrm{O} / \mathrm{NaX}$ catalysts for biodiesel production. Catal. Today, 271, 220-226.

Ruiz, J.R., Mora, M., López, M.I.,Carmona, M.Á., Jiménez-Sanchidrián, C., 2010. Study of the thermal decomposition of a sepiolite by mid- and near-infrared spectroscopies. Polyhedron. 29 (16),3046-3051.

Sabah, E., Çelik, M.S., 2005. Sepiolite: An effective bleaching adsorbent for the physical refining of degummed rapeseed oil. J. Am. Oil Chem. Soc. 82 (12), 911-916.

Singer, A., 1989. Palygorskite and sepiolite. In: Dixon, J.B., Schultze, D.G. (eds): Soil mineralogy and environmental applications. Soil Science Society of America, Madison, Wisconsin, USA, Book Series 7, 555-584.

Soetaredjo, F.E., Ayucitra, A., Ismadji, S., Maukar, A.L., 2011. KOH/bentonite catalysts for transesterification of palm oil to biodiesel.Appl.Clay Sci. 53 (2), 341-346.

Somorjai, G.A., Na, K., 2015. Hierarchically nanoporous zeolites and their heterogeneous catalysis: current status and future perspectives. Catal. Lett. 145 (1), 193-213.

Suarez, M., Garcia-Rivas, J., Garcia-Romero, E., Jara, N., 2016. Mineralogical characterisation and surface properties of sepiolite from Polatli (Turkey). Appl. Clay Sci. 131, 124-130.

Torres-Ruíz, J., López-Galindo, A., Gonzales-López, J.M., Delgado, A., 1994. Geochemistry of Spanish sepiolite-palygorskite deposits: genetic considerations based on trace elements and isotopes. Chem. Geol., 112, 221-245. 
371 Villamiel, M., Corzo, N., Foda, M.I., Montes, F., Olano, A., 2002. Lactulose formation catalysed by

372 alkaline-substituted sepiolites in milk permeate. Food Chemistry. 76, 7-11.

373 Wang,Y., Sun, G., Li, Y., Cai, Z., Teng, Y., Reaney, M.J.T., 2017. $\mathrm{K}_{2} \mathrm{CO}_{3}$-loaded hydrotalcite: A 374 promising heterogeneous solid base catalyst for biolubricant base oil production from waste cooking 375 oils Appl. Catal. B: Envir. 209,118-127.

376 Xu, C., Liu, Q., Xin, R., Li, C., Yang, J., 2013. Application of red mud as a basic catalyst for 377 biodiesel production. J. Envir. Sci. 25 (4), 823-829.

378 Yeniyol, M., 1986. Vein-like sepiolite occurrence as a replacement of magnesite in Konya, Turkey. 379 Clays and Clay Minerals 34, 353-356.

380 Yeniyol, M., 2014. Characterization of two forms of sepiolite and related Mg-rich clay minerals 381 from Yenidoj an (Sivrihisar, Turkey). Clay Miner. 49 (1), 91-108. 